\title{
Base-specific Photocleavage of DNA induced by Nanosecond U.V. Pulsed Laser Radiation or Methylene Blue Sensitisation
}

\author{
Werner Blau,a David T. Croke,b John M. Kelly, c* David J. McConnell,b* Colm OhUigin,'b and \\ Wilhelm J. M. Van der Puttenc \\ Departments of Physics, ${ }^{\mathrm{a}}$ Genetics, ${ }^{\mathrm{b}}$ and Chemistry, ${ }^{\mathrm{c}}$ University of Dublin, Trinity College, Dublin 2, Ireland
}

Excitation of DNA in neutral solution either with short-duration, intense pulses of excimer laser ( $248 \mathrm{~nm})$ radiation or with low intensity red-light $(633 \mathrm{~nm})$ sensitisation by methylene blue causes cleavage of the DNA backbone selectively at guanine.

The development of photochemical procedures which could complement (or even replace) current DNA sequencing methods is of considerable interest. One appoach could be to use base-specific photocleavage of DNA to replace the chemical methods of Maxam and Gilbert. ${ }^{1}$ However as it is known that the photochemistry of DNA is dominated by photoreactions of the bases (e.g. thymine dimerisation) and that breaking of the sugar-phosphate backbone is a very inefficient process, ${ }^{2}$ such a strategy might seem unlikely. We report here that excitation of DNA with short-duration pulses of u.v. radiation causes such cleavage, base-selectively at guanine.

Irradiation of DNA with 'picosecond' 3,4 or 'nanosecond' ${ }^{5-7}$ pulses of u.v. radiation has recently been shown to cause rupture of the DNA backbone. Our present experiments have been carried out with a standard (Lambda Physik EMG 102) KrF excimer laser used to provide u.v. pulses ( $248 \mathrm{~mm}$; pulse-width $22 \mathrm{~ns}$; energy $70 \mathrm{~mJ}$ ). The laser beam is focussed down so as to excite uniformly a small (4-50 $\mu$ ) sample of DNA solution contained in a tube of diameter 1.5 or $2.3 \mathrm{~nm}$. By suitable focussing and filtering of the beam it is possible to control the intensity of the pulse within the range $1 \times 10^{9}-5 \times 10^{12} \mathrm{~W} \mathrm{~m}^{-2}$. The cleavage of DNA by this radiation has been studied using covalently closed circular (plasmid pBR322) DNA. As expected from the earlier reports, 5,6 it was found that low intensity light caused little change in the electrophoretic behaviour of this DNA, whereas at the same fluence but at intensities greater than $10^{9} \mathrm{~W} \mathrm{~m}^{-2}$ single strand nicking occurred and the open circular and linear forms were produced. This intensity dependence indicates that the bond-rupture reaction is initiated by multi-photon (probably consecutive two photon) excitation, as previously observed with picosecond excitation..$^{3,4}$ At an intensity of $5 \times$ $10^{10} \mathrm{~W} \mathrm{~m}^{-2}$, the quantum yield for single strand cleavage was found to be $c a$. $1-2 \times 10^{-5}$. The base specificity of the cleavage was determined using a $5^{\prime}$-terminus ${ }^{32} \mathrm{P}$-labelled DNA sample ( 4.3 kbase EcoRI-Hind III restriction fragment of pBR322) and subsequent electrophoresis on sequencing gels in parallel with the products formed by conventional Maxam-Gilbert chemical treatment of the same fragment. ${ }^{1 \dagger}$ Some samples of irradiated DNA were also treated with alkali

† Photolysis conditions. (i) For the KrF laser, $50 \mu \mathrm{l}$ of labelled DNA in a horizontally held tube (internal diameter $2.3 \mathrm{~mm}$ ) were given 20 pulses of $50 \mathrm{~mJ}$ at an intensity of $5.5 \times 10^{11} \mathrm{~W} \mathrm{~m}^{-2} .25 \mu \mathrm{l}$ of the sample were then treated with $0.23 \mathrm{M} \mathrm{NaOH}$ at $70^{\circ} \mathrm{C}$ for $30 \mathrm{~min}$. Samples were precipitated in ethanol, resuspended in $80 \%$ formamide, and denatured for $2 \mathrm{~min}$ at $90^{\circ} \mathrm{C}$ before loading onto a $8 \%$ polyacrylamide- $7 \mathrm{M}$ urea DNA sequencing gel. (ii) $20 \mu \mathrm{l}$ samples of $\mathrm{MB}^{+}$and DNA ([Nucleotide] $=40 \mu \mathrm{M}$, [Nucleotide $] /\left[\mathrm{MB}^{+}\right]=15$ ) were irradiated for $30 \mathrm{~min}$. Samples were then dried, resuspended in $80 \%$ formamide, denatured for $5 \mathrm{~min}$ at $95^{\circ} \mathrm{C}$, and electrophoresed as above. It may be noted that the denaturing conditions used ( $2-5 \mathrm{~min}$ at $90^{\circ} \mathrm{C}$ ) might possibly be sufficient to induce some additional cleavage at sites where the bases had been modified during irradiation. before electrophoresis. Sections of the autoradiograph obtained in these experiments are shown in Figure 1 (Lanes 3-5). It may be noted from the pattern of the bands that cleavage is observed only at guanine and that a band is present for each guanine base in the sequence. The band intensity varies considerably from site to site. Interestingly it is also found that the electrophoretic mobility of the cleavage products not treated with alkali is less than that of the Maxam-Gilbert fragments whereas samples which had been treated with alkali after irradiation have apparently identical electrophoretic properties to those of the Maxam-Gilbert chemically-cleaved guanine products. $\ddagger$

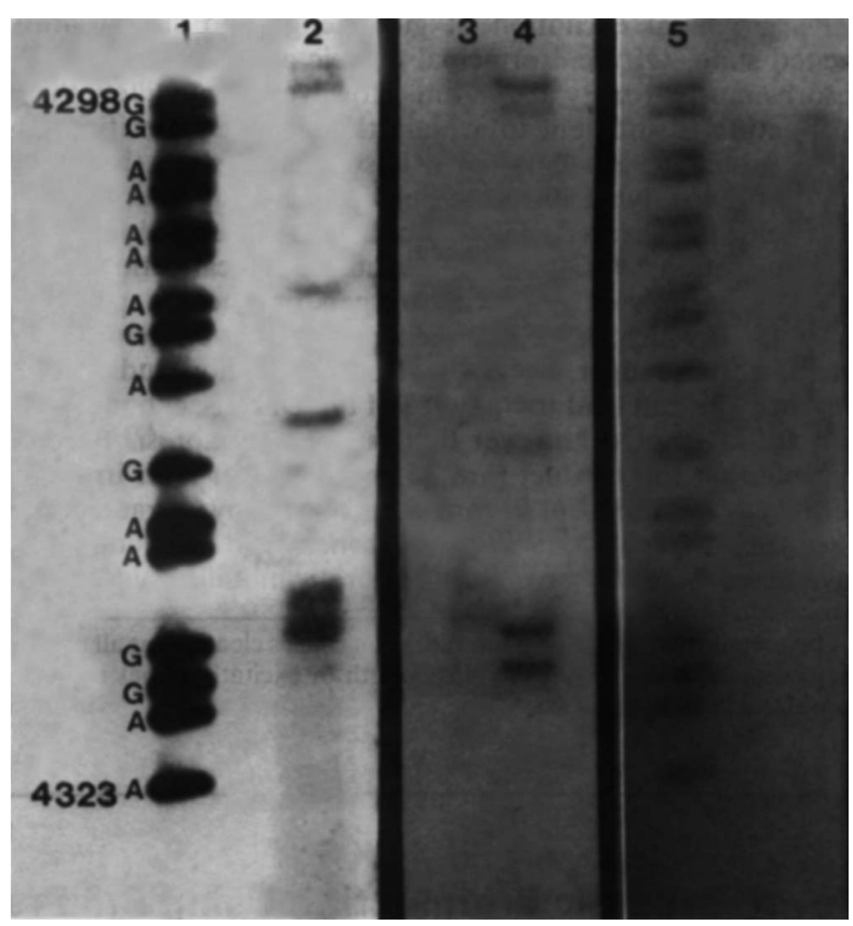

Figure 1. High resolution electrophoresis gel of the photolysis of ${ }^{32} \mathrm{P}$ 5 '-end labelled DNA. Lanes from two different sequencing gels (Lanes $1-2 ; 3-5$ ) show Maxam and Gilbert chemical cleavage products run in parallel with photolysed samples of the same DNA. (Region shown contains bases 4298-4323 of pBR322.) Lane 1, Maxam and Gilbert $\mathrm{G}$ (guanine) + A (adenine). Lane 2, methylene blue-photosensitised products. Lane 3 , excimer laser-induced photoproducts. Lane 4, alkali-treated laser photoproducts. Lane 5, Maxam and Gilbert $\mathrm{G}+\mathrm{A}$ products.

\# In the Maxam-Gilbert procedure ${ }^{1}$ cleavage at guanine is induced by reaction of the DNA with dimethylsulphate and subsequent treatment with piperidine. This causes cleavage at the $\mathrm{C}\left(5^{\prime}\right)-\mathrm{O}$ bond on the 5 '-side of the modified base, forming a labelled DNA fragment with a 3 '-phosphoryl group. 
Dye-sensitised photochemistry might also possibly be baseselective, and indeed it was reported some years ago that low intensity visible-light irradiation of aerated solutions of methylene blue $\left(\mathrm{MB}^{+}\right)$-DNA mixtures damaged the DNA, such that subsequent alkali treatment led to cleavage specifically at guanine. ${ }^{8}$ To investigate this system further we have examined by electrophoresis the products formed upon irradiation of $\mathrm{MB}^{+}-\mathrm{DNA}$ mixtures using low intensity ( $3 \mathrm{~mW}$ ) red light $(633 \mathrm{~nm})$ from a continuous HeNe laser. We observed that cleavage of the DNA occurs without alkali treatment (either in aerated or argon-flushed solutions), with quantum yields in the range $1-3 \times 10^{-7}$ depending on conditions and that the cleavage occurs at guanine. The cleavage product migrates more slowly than the corresponding Maxam-Gilbert product, with a mobility similar to that of the excimer laser product described above. (There is also a minor product observed for most bands, which has the same mobility as the Maxam-Gilbert product.) Subsequent alkali treatment is known to give products having identical mobility to that of the Maxam-Gilbert products. ${ }^{8}$

While a more extensive series of experiments will be required to determine the mechanism responsible for the guanine-specific cleavage of DNA following pulsed u.v. laser excitation, some comments can be made at this stage. Firstly, as the intensity dependence indicates consecutive two-photon excitation of a base, the selectivity may be caused in part by the preferential excitation of guanine ground state or its excited state. Of the 4 principal nucleic acid bases, guanine absorbs most strongly at $248 \mathrm{~nm}$. However it is unlikely that this feature is sufficient to explain the observed specificity. More probably, excitation of a base excited state (perhaps mainly the low-lying thymine triplet ${ }^{2}$ ) causes photoionisation and yields the base's radical cation. If this is then followed by hole migration, ${ }^{9,10} \mathrm{G}^{\cdot+}$, the most stable radical cation, will result. Reaction of $\mathrm{G}^{\cdot+}$ with oxygen produces a peroxyradical, 11,12 which can subsequently abstract hydrogen atoms from the ribose sugar. It is known from $\gamma$-radiation studies that such radicals can lead to cleavage of the DNA backbone.11,13 It should be noted however that our electrophoresis results indicate that the product formed upon excimer laser irradiation of DNA is different from those produced by $\gamma$-irradiation, where the two fragments detected from 5 '-end labelled DNA have been shown to have electrophoretic mobilities identical

$\S$ The recent report ${ }^{5}$ that $266 \mathrm{~nm}$ radiation causes cleavage at all bases may possibly indicate that the wavelength of excitation does exert a considerable influence. and greater than the Maxam-Gilbert fragment. These have been identified as species having respectively phosphoryl and glycollate termini. ${ }^{14}$ The decreased mobility of the excimer laser product is consistent with a compound formed by cleavage of the $3^{\prime}$-phosphodiester bond and still containing a substantial fragment of the modified guanine nucleoside. This fragment may be removed by alkali treatment, which causes cleavage at the 5 '-phosphodiester bond, a feature consistent with the observed increase in mobility (see Figure 1). The fact that a product with similar mobility is formed by $\mathrm{MB}^{+}$. sensitised reaction might indicate that in this case too the cleavage is initiated (at least in part) by the formation of guanine radical cations.

We thank British Petroleum Venture Research, Arthur Guinness and Sons Ltd., the Investment Bank of Ireland, and the Departments of Education of Ireland and the Netherlands for financial support.

Received, 18th December 1986; Com. 1802

\section{References}

1 A. M. Maxam and W. Gilbert, Methods Enzymol., 1980, 65, 499.

2 'Photochemistry and Photobiology of Nucleic Acids,' ed. S. Y. Wang, vols. I and II, Academic Press, London, 1976.

3 D. N. Nikogosyan and G. G. Gurzadyan, Laser Chem., 1984, 4, 297.

4 G. G. Gurzadyan, D. N. Nikogosyan, T. S. Balmukhanov, and G. B. Zavilgekskij, Photobiochem. Photobiophys., 1982, 4, 87.

5 E. I. Budowsky, O. I. Kovalsky, D. Y. Yakovlev, N. A. Simukova, and L. B. Rubin, FEBS Lett., 1985, 188, 155.

6 D. Schulte-Frohlinde, J. Opitz, H. Gorner, and E. Bothe, Int. J. Radiat. Biol., 1985, 48, 397.

7 M. Johnson-Thompson, J. B. Halpern, W. M. Jackson, and J. George, Photochem. Photobiol., 1984, 39, 17.

8 T. Friedmann and D. M. Brown, Nucleic Acids Res., 1978, 5, 615.

9 M. D. Sevilla, J. B. D'Arcy, K. M. Morehouse, and M. L. Engelhardt, Photochem. Photobiol., 1979, 29, 37.

10 A. Graslund, A. Ehrenberg, A. Rupprecht, and G. Strom, Photochem. Photobiol., 1979, 29, 245.

11 (a) C. von Sonntag, U. Hagen, A. Schon-Bopp, and D. Schulte-Frohlinde, Adv. Radiat. Biol., 1981, 9, 109; (b) D. Schulte-Frohlinde, and C. von Sonntag, in 'Oxidative Stress,' ed. H. Sies, Academic Press, London, 1985, ch. 2, pp. 11-40.

12 P. J. Boon, P. M. Cullis, M. C. R. Symons, and B. W. Wren, J. Chem. Soc., Perkin Trans. 2, 1984, 1393.

13 F. Hutchinson, Prog. Nucleic Acid Res., 1985, 32, 115.

14 (a) W. D. Henner, S. M. Grunberg, and W. B. Haseltine, J. Biol. Chem., 1982, 257, 11750; (b) W. D. Henner, L. O. Rodriguez, S. M. Hecht, and W. A. Haseltine, ibid., 1983, 258, 711. 